\title{
Controlling Ourselves: Emotional Intelligence, the Marshmallow Test, and the Inheritance of Race
}

\author{
Michael E. Staub
}

In 1995, when psychologist Daniel Goleman published Emotional Intelligence, a treatise that topped best-seller lists for more than a year and went on to sell 5 million copies worldwide, he introduced a popular audience to a concept that had been circulating in psychology circles for some time. The idea that people possessed an "emotional intelligence" (EI) was not original with Goleman. There had already been research by several psychologists, including Howard Gardner, Peter Salovey, and Jack Mayer, that had mapped out a position that intelligences were multiple and that noncognitive skills (like self-awareness, motivation, and empathy) played as large a role, if not a far greater role, in how a person's life turned out than did that individual's IQ. ${ }^{1}$ Not incidentally, psychologists and educators who championed the centrality of noncognitive skills were posing a direct challenge not only to experts across the political spectrum who believed in the value of IQ as a metric. They were - and quite significantly — challenging right-wing (and often explicitly racialized) theories that stated how traditional IQ testing represented the most accurate predictor of a person's capacity for achievement in life. Thus, the ascent of a concept of EI in the mid-1990s proved most timely, as it imparted a powerful (implicitly antiracist) alternative to a view that cognitive intelligence trumped all other aptitudes - especially in the wake of (and fierce controversy surrounding) the 


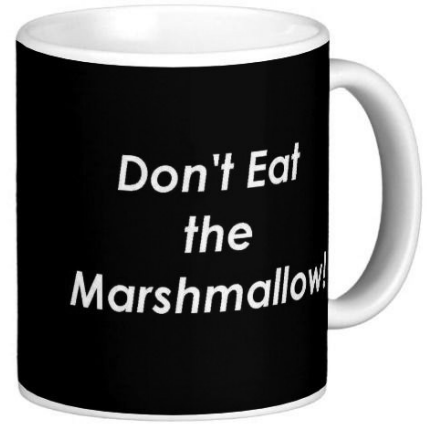

Figure 1: A "Don't Eat the Marshmallow!" coffee mug, currently available at http://www.zazzle.com. Image reprinted by permission.

publication of Richard Herrnstein and Charles Murray's The Bell Curve: Intelligence and Class Structure in 1994.

A history of EI cannot be told apart from a history of race and class in the United States - and this has everything to do with one further dimension of EI and that is the significance to it of the ideal of self-control [Figure 1]. Goleman's book had placed an extraordinarily strong emphasis upon self-control as a key component of EI and in all the laudatory reception no one thought to interrogate the genealogy of that emphasis. It is only by tracing the often complex (frequently obliquely coded but nonetheless palpable) relationships between debates about the value of self-control among psychologists, criminologists, education experts and policymakers since the 1930s (and the shifting beliefs about social change and individual personality and perfectibility in which they are embedded) that the inextricability of EI—and the lessons drawn from talking about it—from the racial and class politics of the United States becomes clear.

Notably, the emphasis on self-control had not been shared by earlier proponents of the EI concept. Rather, as Salovey and Mayer had written in 1990, EI was a much broader and diffuse "set of skills" that included "the accurate appraisal and expression of emotion in oneself and in others, the effective regulation of emotion in self and others, and the use of feelings to motivate, plan, and achieve in one's life."' But Goleman recast EI as having almost everything to do with an ability to exercise self-discipline. It was a point he hammered in Emotional Intelligence, writing, for instance, that "a sense of self-mastery, of being able to withstand the emotional storms that the buffeting of Fortune brings rather than being 'passion's slave,' has been praised as a virtue since the time of Plato." He added, "There is perhaps no psychological skill more fundamental than resisting impulse." He wrote elsewhere, "The bedrock of character is self-discipline; the virtuous life, as philosophers since Aristotle have observed, is based on self-control." He put the good that came with achieving self-control in terms that were quite dramatic: "The capacity to impose a delay 
on impulse is at the root of a plethora of efforts, from staying on a diet to pursuing a medical degree." ${ }^{\prime 3}$ Goleman left little doubt as to which noncognitive skill he most associated with EI.

What this emphasis on self-control as a crucial - if not the crucial - component of EI has to do with the history of race and class in the United States forms the subject of this essay. And it leads us directly to my second central subject since to make the case that self-control represented a key aspect of EI, Goleman relied almost entirely on a (then) not-well-known series of psychological experiments that had been conducted by a Stanford personality theorist named Walter Mischel. At various points dating back to the 1950s, Mischel had given children a basic choice. Did the child want the smaller notebook now or a larger notebook a week later? Would she accept the smaller magnifying glass immediately or wait for a bigger magnifying glass a week later? ${ }^{4} \mathrm{Or}$ - as the test span shortened over time - would the child choose to gobble up one marshmallow right away, or would he be able to wait fifteen minutes for the tester to return so that he could enjoy two? Regardless of the rewards involved and the details adapted, the core of Mischel's experimental design remained much the same. ${ }^{5}$ For instance, a report on the first of these gratification delay experiments (conducted in 1957) described how a researcher presented young children with a larger and a smaller piece of candy and then announced, "I would like to give each of you a piece of candy but I don't have enough of these (indicating the larger, more preferred reinforcement) with me today. So you can either get this one (indicating the smaller, less preferred reinforcement) right now, today, or, if you want to, you can wait for this one (indicating) which I will bring back next Wednesday (one week delay interval). ${ }^{96}$ Each child then had to decide what to do next.

Importantly, as the published reports growing out of Mischel's experiments piled up, Mischel began to identify an ever-widening array of correlations, all connected to the single decision of the child to yield or not to yield to his or her temptations. High delayers, Mischel posited, were more socially responsible and less likely than poor delayers to engage in delinquent behavior. ${ }^{7}$ High delayers were more mature and autonomous and possessed stronger achievement skills than poor delayers. ${ }^{8}$ On the flip side, the inability to control impulses was correlated with children who lacked "a permanent father or father-figure." These were the sort of hypotheses that clearly came decades later to fascinate Goleman - and that Goleman supplemented with his own spin that gratification delay was a skill that could be acquired: "There is ample evidence that emotional skills such as impulse control and accurately reading a social situation can be learned." Thus, all individuals (not only preschoolers) had the "meta-ability" to resist immediate temptation, but not everyone - yet — had the EI required to do so. But they could improve themselves. ${ }^{10}$

In more recent years, the so-called marshmallow test—as read through the lens of Goleman's concept of an EI that can be mastered with practice and training - fairly swept through the advice-giving culture of the United States. In fact, it would be hard to overestimate the impact and influence of the marsh- 
mallow test on general assumptions in the United States about what it takes to lead a happier, more fulfilling and productive existence. The self-help and popular psychology industry found the marshmallow test amenable to a small mountain of motivational agendas - from marriage and relationship manuals to how-to investment books. For instance, there were the instructive-if contradictory-invocations of the marshmallow test, on the one hand, in a guide geared to helping people exercise better "self-control in an age of excess" and, on the other hand, in a text on how to "come out ahead in hard times" (by keeping your eye "on the marshmallow!"). ${ }^{11}$ There were as well countless management and business publications that cite self-control (and often also Mischel's marshmallow test) in discussions of how and why EI represents "the sine qua non of leadership," as Goleman definitively observed in the Harvard Business Review in $1998 .{ }^{12}$ A guide on how to lead a more spiritually meaningful life asked, "Do we have the patience and vision to achieve what we really want as our end goals or do we lose sight of the prize because of the big, white marshmallow in front of us?"13 The marshmallow test turned up in books on how to make a million dollars through clever investments and how to avoid the pitfalls of so-called "short-termism" (because "short-termism causes us to eat the marshmallow"). ${ }^{14}$ By the time he published The Marshmallow Test: Mastering Self-Control (2014), Mischel himself could not agree more, having fully adopted the framework of EI for how to present his own research. But what was being forgotten in all this new enthusiasm for EI and the marshmallow test was the fact that social psychological research into the dynamics of self-control had actually had a surprisingly long - and, as it happens, quite ideologically ambiguous-history. ${ }^{15}$

\section{Self-Control and Class}

The ideological ambiguity of the marshmallow test and the ways in which the test has become completely interwoven with popular discussions of race (however coded) and class may be illustrated with the example of an op-ed piece from 2006 (titled "Marshmallows and Public Policy") by New York Times columnist David Brooks. Here Brooks observed how crucial it was for think tanks to learn the lessons of the marshmallow test - precisely because the test identified "core psychological traits like delayed gratification skills." Not grasping the import of the marshmallow experiment (or so Brooks lamented) meant that policy experts were "just dancing around with proxy issues" while "not getting to the crux of the problem." Acknowledging the damage done by poverty ("children from poorer homes are more likely to have their lives disrupted by marital breakdown, violence, moving, etc."), Brooks nonetheless derided the idea of "structural reforms" and "structural remedies," noting that their results "are almost always disappointingly modest." Instead, he emphasized that "for people without self-control skills, . . . life is a parade of foolish decisions: teen pregnancy, drugs, gambling, truancy and crime," and thus that policymakers 
should instead be asking "core questions, such as how do we get people to master the sort of self-control that leads to success?"16

While such a conclusion may appear to be free of ideological bias, a review of historical perspectives reveals quite the opposite. For instance, and despite the ways in which Brooks presented his thesis about the failure to delay gratification as self-evidently a road to disaster, this perspective was not in fact the slightest bit self-evident in prior decades. Instead, there was an active debate about the possible correlations between race, class, personality, and life success, as well as a debate about the directions of causation.

African American social anthropologist and psychologist Allison Davis, professor of education at the University of Chicago and an early postwar scholar of self-discipline, argued in 1948 against a view that class differences were the result of an inability to defer gratification. Davis was unconvinced of the general usefulness of gratification delay. More importantly, his research showed that socioeconomic status was not a consequence of personality traits. Davis's findings had implications for education but also for thinking about the intersections of race and class.

For starters, Davis insisted on the need for scholars and policymakers to grasp that lower-class culture valued entirely different skills and competencies than middle-class culture did. Davis found "pathetic," for instance, the effort to measure lower-class children by middle-class standards of docility and verbal fluency. ${ }^{17} \mathrm{He}$ called for an educational approach that encouraged children across all classes to be given opportunities for problem solving and that cultivated their abilities to reason, analyze, invent, and imagine. Davis reasoned that if lower-class individuals did not restrain various impulses, it was because they were poor; they were not poor because they were impulsive. Davis focused on how various "systems of control" served to organize Americans along strict class lines, and if there existed "certain gross differences" in behavior between groups, those differences had everything to do with class distinctions. Furthermore, Davis's research empirically demonstrated that there were many more similarities between middle-class black and middle-class white families - and many more differences within the black community across class divisions. Therefore, Davis hypothesized that all and any differences between whites and blacks "are not related to hereditary, biological, or 'racial' factors." Ultimately, Davis's conclusion was not that the individuals needed to work on themselves but rather that the society needed to change. If educators truly wanted to witness improvements in "the personality development of Negro adolescents," it would become necessary "to reorganize the social and economic structures" of the United States since only an economic restructuring could conceivably "decrease the social wastage of human lives in our society."18

Notable, too, was that Davis was part of a much larger set of social scientific conversations about the politics of self-control. He was hardly a lone voice. In one line of discussion, sociologists, psychologists, and educators in the 1930s and 1940s found that African Americans who sought to adapt to 
white middle-class standards of self-renunciation were, due to racism, all too often denied the respect and benefits they had expected and hoped to receive. In 1937, psychologist John Dollard wrote that "it can be assumed that human beings never give up possibilities for gratification just for fun; self-restraint is difficult and there must be an adequate social premium on it. The general formula seems to be that the middle-class Negroes sacrifice the direct impulse gains of the lower-class group and expect to have in return the gratifications of prestige and mastery. They expect to get them, but the fact is that they are not always paid out according to our cultural model." Like Allison Davis, Dollard too was convinced that efforts on the part of individuals to alter their personal behavior were not enough. "Lower-class culture cannot be changed in a more restrictive direction," Dollard concluded, "until the social situation is changed and the economic and status rewards for labor and self-discipline are increased."19

Another line of discussion had to do with class differences also among whites. Over and over, investigators established that patterns of child rearingincluding weaning, toilet training, restrictions on movement, and encouragement to take on individual responsibilities - differed dramatically across class lines, with significant effects on the personality structures of the individuals raised in those two divergent worlds. A widely circulated article by psychologist Martha C. Ericson in 1946 (based on 100 interviews with middle-class and lower-class white mothers in Chicago) found that "middle-class children and lower-class children live in well-differentiated cultures" and that the differences showed up in the resulting personalities; middle-class children were likely to be "subjected to more frustration in learning" and to be "more anxious" than their lower-class counterparts. ${ }^{20}$ When educator and psychologist Robert J. Havighurst gave a fuller report on Ericson's findings and incorporated also her research on African American parents, "the results show that the same types of differences exist between middle and lower-class Negroes as between middle and lower-class whites." Like Ericson, Havighurst took the view that the childrearing practices of middle-class parents caused children to experience "more frustrations of their impulses" than did the practices of working-class parents. ${ }^{21}$

The implicit suggestion that the restrictions on impulses might cause malformations of character in middle-class children found fullest expression in 1946 in Arnold W. Green's “The Middle Class Male Child and Neurosis.” Basing his theories on growing up in a small Massachusetts community of Polish immigrant and native-born families, Green noted a relative absence of neurotic symptoms among the working-class immigrant children in contrast to a concomitant prevalence of emotional problems exhibited by the economically better-situated native-born children. Green leveled his critique at the white middle-class family as a place where the father saw his son as sapping emotional energies and resources better conserved to advance his own status and material progress. And mothers found themselves trapped in a domestic existence where every waking moment was devoted to "the drudgery of housecleaning, diapers, and the preparation of meals." The marriage life (and the marriage bed) 
languished as a consequence, as the wife watched how "half her working day is spent doing something she does not like, [while] the rest is spent thinking up ways of getting even with her husband." The child caught in this nexus of pain and internalized self-denial soon discovered that "the living room furniture is more important to his mother than his impulse to crawl over it," a fact that "unquestionably finds a place in the background of the etiology of a certain type of neurosis, however absurd it may appear."’22

Sociologists through the 1950s and into the 1960s persisted in arguing that when middle-class parents enforced delayed gratification strategies, these produced neuroses in children. Sociologist Albert K. Cohen's Delinquent Boys (1955), a pioneering study in subcultures - however counterintuitively, given its title - perpetuated the negative view associated with middle-class attitudes and mores. Cohen scarcely moderated his disdain for middle-class parents who placed an unhealthful premium on their children's "readiness" and "ability to postpone and to subordinate the temptations of immediate satisfactions and self-indulgence in the interest of the achievement of long-run goals." Cohen was overtly sarcastic when he discussed how middle-class parents acted as though "industry and thrift, even divorced from any conscious utilitarian objectives, are admirable in themselves." More often than not, the life of a middleclass child, Cohen added, was "geared to a timetable, to the future as well as the present," and as a consequence the child became "constantly aware of what his parents want him to be and to become." None of these values, Cohen emphasized, had much to do with love. On the contrary, middle-class children were socialized early to recognize that any love their parents might express toward them was "precarious and contingent": "something to be merited, to be earned by effort and achievement." 23

Sociologists who explored the styles and behaviors of "delinquent" youth in the 1950s and early 1960s also found the concept of an emotionally warped middle class to be enormously productive. For one thing, and as paradoxical as it may sound, this concept enabled sociologists to argue that there were ruptures and continuities between "straight" and "delinquent" worlds. No one wanted to play by the rules all the time. It was not only delinquents who had the itch to escape the rat race. Everyone sought their "kicks," and so a search for thrills could hardly be labeled "a deviant value, in any full sense," but actually existed "side by side with the values of security, routinization, and the rest." As a significant reflection from 1961 on the phenomenon of delinquency summarized, "In other words, the middle class citizen may seem like a far cry from the delinquent on the prowl for 'thrills,' but they both recognize and share the idea that 'thrills' are worth pursuing." 24

By the early 1960s, the sociologist and historian William Sewell-disagreeing strongly with the ascription of unhappy uptightness to the middle class and confirming the newer trend that found middle-class parents actually often to be the more permissive ones - argued that it was in fact difficult to find any clear correlation between personality and socioeconomic status. Sewell found fault 
with Davis, Havighurst, and Ericson's conclusions on the restrictiveness of middle-class mothers and the ensuing supposed greater frustration of middle-class children's impulses. But his irritation was directed primarily at what he saw as the overenthusiastic reception of those particular conclusions by the many social science and social work experts who had also uncritically absorbed Green's portrait of the neurotic male middle-class child desperate to please his parents. Sewell was articulately dismissive of how a narrowly Freudian fixation on the very early childhood years, especially on breast and bowels, had gone unchallenged across the social sciences for more than fifteen years. He was most adamant in emphasizing that extant recent studies "offered absolutely no support for the notion that middle-class children more commonly exhibit neurotic personality traits than do children of lower-class origins. ${ }^{.25}$ And he made a raft of suggestions for how large-scale research on the three-way relationship between socioeconomic status, child-rearing practices, and personality adjustment might be designed more carefully in the future. Missing from Sewell's survey, however, was any attention to the original context in which Davis, Havighurst, and Ericson were writing and the urgent need they had felt to refute racist assumptions about African Americans and thus to disaggregate race from class.

\section{Predicting Deviance}

In the 1950s, research about self-control and character development had also begun to have a major impact in the interdisciplinary field of criminology. Arguably, no single text in this field loomed larger than Unraveling Juvenile Delinquency (1950), a major study conducted by Harvard criminologists Eleanor Glueck and Sheldon Glueck. The Gluecks began their research already in the late 1930s, at which time they then devoted a full ten years to a longitudinal analysis of 500 delinquent and nondelinquent boys. The Gluecks concluded that there were a multitude of factors - temperamental, intellectual, familial, and biological - that contributed to a boy's potential for the development of delinquent behavior later in his life. They hypothesized that the boys who grew up in an environment that was "little controlled and culturally inconsistent" more readily tended to "give expression to their untamed impulses and their self-centered desires by means of various forms of delinquent behavior." One almost invariably found in the future delinquent, the Gluecks noted, that "tendencies towards uninhibited energy-expression" had been "deeply anchored" in the child's "psyche and in the malformations of character during the first few years of life." ${ }^{26}$ There were, or so the Gluecks surmised, remarkable continuities between childhood deviance and adult criminality.

The Gluecks additionally designed a Social Prediction Table (SPT) to be used by social workers, psychologists, educators, and criminologists to forecast a young child's chances of growing from juvenile delinquency into adult criminality. In the course of the 1950s, a number of studies conducted around the United States (as well as Japan and France) tended to validate the usefulness 
of the SPT. ${ }^{27}$ By 1960, and building directly on the Gluecks' research, the New York Times reported how a longitudinal study of "likely bad boys" conducted in the Bronx had established that "the detection of potential delinquency in children under 6 years old has been reduced to a relatively exact science." 28 Notable as well was the fascinating study, Deviant Children Grown Up (1966), which further confirmed the Gluecks' analysis. Here sociologist Lee Robins had reviewed discarded records from a child guidance clinic in St. Louis from the 1920s and 1930s and then had tracked down and conducted follow-up interviews with 100 individuals - now in their forties - who had received counseling at the clinic thirty years earlier. What Robins concluded - as had the Gluecks in the 1950 s - was that "adult antisocial behavior virtually requires childhood antisocial behavior." ${ }^{29}$ Woven through this thread of research was a general conclusion that exposure to "low moral standards" in the homes where children grew up was an absolutely key factor in predicting future delinquent and criminal behaviors. ${ }^{30}$

Efforts to devise a successful predictive test for childhood deviancy and attempts to dissect the social psychological mechanisms of delay and reward were soon to find common cause. This interdisciplinary meeting of methodologies did not, however, happen all at once, perhaps because the history of delay and reward had long involved the use of animals (e.g., rats or pigeons) as trial subjects. The efforts to theorize a relationship between a delay in reinforcement and learning response had their origins in the first decades of the twentieth century. ${ }^{31}$ These experiments had either typically involved the use of delayed rewards to train animals to perform specific tasks or had involved an effort to predict how variable delays during the acquisition of a skill correlated with greater resistance to extinction of those skills. ${ }^{32}$ Once experimental studies turned to the use of children as subjects in the course of the 1950s, these early tests also investigated principally the causal impact of reinforcement delay on learning and skill acquisition. ${ }^{33}$ A predictive link between deviancy and reinforcement delay as an area of inquiry arrived somewhat later.

Making this connection between a child's struggle to choose between delayed or immediate gratification and the development of a personality that could (or could not) control deviant behavior was an innovation that can be credited to Walter Mischel. The first delayed gratification experiment Mischel ever conducted involved field research with several dozen "Negro" and "Indian" children between the ages of seven and nine on the West Indies island of Trinidad. Strikingly, Mischel sought to challenge the crude generalizations that "the Negroes are impulsive, indulge themselves, settle for next to nothing if they can get it right away, do not work or wait for bigger things in the future but, instead, prefer smaller gains immediately," while "the Indian is said to deprive himself and to be willing and able to postpone immediate gain and pleasure for the sake of obtaining greater rewards and returns in the future." (Mischel presented these generalizations as each group's own expressed prejudices about the other.) In his experiment, Mischel did find some correlation between ethnic 
group and choice behavior (with more "Negro" than "Indian" children seeking immediate gratification). But he also found evidence that "the presence or absence of the father" in the home mattered just as much - regardless of the child's racial background. And he likewise found that older children were better able to delay_again, regardless of race. This suggested that an ability to resist immediate temptation represented "a learned behavior which is, in part, a function of the expectancy that the promised reinforcement will issue from the social agent in spite of time delay." ${ }^{34}$ In short, at this point Mischel's analysis included attention to the question of how reliably the child could count on the testing adult to come through with that larger piece of candy.

Mischel's subsequent decision to moralize about the meanings of delayed gratification became evident little by little over a period of some years. It was a decision linked to Mischel's interest in extant psychological research on maladaptive social behaviors on the one hand and his concern with correlations between social learning and maturity on the other. ${ }^{35}$ The more emotionally healthful a child was, Mischel began to hypothesize, the more capably that child could delay gratification; this was due to the fact that he or she possessed an ability to think through the consequences of a present action in the future. "A person does not have to perform particular behaviors himself to learn their consequences," Mischel would explain in 1968, choosing an unusual but certainly evocative example to clinch his argument: "For example, a man does not have to be arrested for wearing dresses in public to learn some of the consequences of transvestism. Any information that alters the person's anticipations about the probable outcomes to which a behavior will lead should also change the likelihood that he will engage in the behavior." ${ }^{\prime 36}$ Whether and how children developed behaviors that were (conventionally conceived as) deviant behaviors began to move from the margins to the center of social psychological thinking about a capacity for delayed gratification in children.

Already in 1964, Mischel made explicit his hypothesis that there was a correlation between social deviance and incapacity to delay gratification. Mischel began to position his research into gratification delay as being in direct lineage with studies that had "investigated resistance to temptation, and tried to correlate the subject's reactions when under pressure to violate his standards with indices of 'guilt' and with aspects of parental disciplinary techniques." ${ }^{37}$ In one of the few experiments Mischel conducted that utilized the strategy of deception of test subjects, teenagers kept their own scores while they played an arcadestyle game, but the points they were able to earn were rigged so that "the scores they got made it impossible to win a badge: to get a badge, they had to cheat by falsifying their scores, and to win a better badge they had to fake it even more." ${ }^{\prime 38}$ Although this test had concerned frustrating circumstances in which actual skill was never appropriately rewarded rather than a test for deferring a gratification that could be trusted eventually to arrive, Mischel extrapolated more broadly: "If the subject is to resist the temptation and to refrain from deviant behavior, he must be able to defer immediate gratification." ${ }^{39}$ A new social 
psychological paradigm that emphasized the responsible need for self-control was born.

\section{Self-Control and Public Policy}

The Negro Family: The Case for National Action, written by political scientist (and assistant secretary of labor) Daniel Patrick Moynihan and published by the U.S. Department of Labor's Office of Policy Planning and Research in 1965, likely still remains best remembered - and reviled - for making an argument that the African American community suffered from a "tangle of pathology." Chief among these pathologies, or so Moynihan held, was that the black family "has been forced into a matriarchal structure which, because it is so out of line with the rest of the American society, seriously retards the progress of the group as a whole." ${ }^{40}$ Intended to call attention to the long-term damages caused by white racism, the Moynihan Report achieved an opposite effect, quickly becoming "the focal point for one of the more vociferous public debates about policy in the history of the nation," while Moynihan himself "was pilloried as a racist and the foremost neoconservative on matters of race." backlash against the Moynihan Report was sustained and intensely hostile. ${ }^{42}$ As historian Ellen Herman astutely observed, civil rights activists and their supporters assailed Moynihan for implying that the problems that afflicted the African American family "were primarily personal and psychological" rather than acknowledging how "racial oppression produced social pathology rather than vice versa." Thus, or so his critics asserted, what Moynihan suggested was that "institutional racism and discrimination could be deemphasized or even eliminated as a terrain of governmental action." ${ }^{43}$ The Moynihan Report represented, psychologist and political activist William Ryan famously declared in 1971, a classic case of "blaming the victim." ${ }^{44}$ This characterization has largely stuck to the Moynihan Report over the past half century. ${ }^{45}$

At the same time, the Moynihan Report brought little that was new to light in its explanations for the root causes of African American poverty. Rather, what the Moynihan Report did was cull analyses from several well-regarded expert texts in the behavioral and social sciences. For instance, and notably, its discussions of black family life made repeated references to A Profile of the Negro American (1964) by social psychologist Thomas Pettigrew. ${ }^{46}$ And social psychological research informed the report in at least one additional and important respect.

This had to do with the psychological roots of juvenile crime and delinquency. Citing several of Mischel's early experiments, the Moynihan Report accepted as simple fact that an individual's ability to defer gratification correlated with that individual's family structure. Children in "fatherless homes" sought out "immediate gratification of their desires," and those youth (in their "hunger for immediate gratification") were, in turn, "more prone to delinquency, along with other less social behavior." Turning back to the work of Petti- 
grew, the report added that boys from "high delinquency neighborhoods" raised in "stable, intact families" were able to resist - and rise above - the misfortune of their surroundings. ${ }^{47}$ Although it has been largely unacknowledged in the voluminous scholarship on the Moynihan Report, the report thus promoted a hypothesis that gratification delay enabled persons to advance socioeconomically - while self-indulgence condemned persons to a life replete with personal problems and squandered opportunities. ${ }^{48}$

A concept that an inability to delay gratification might be linked to African American poverty persisted in the public policy literature of the late 1960s and early 1970s. In 1968, the Manpower Report of the President addressed a concern that "social-psychological factors," which included "attitudes, aspirations, motivation (especially achievement motivation)" as well as an "ability or willingness to defer gratification," represented "barriers to employment" and thus provided "explanations of the job behavior of low-income Negroes and others who have difficulty in getting and keeping jobs." ${ }^{49}$ Political scientist Edward Banfield's The Unheavenly City (1968) was saturated with (racially coded) assumptions about the inability of poor people to delay gratification. For instance, Banfield observed how "the lower-class individual lives from moment to moment. ... He is therefore radically improvident: whatever he cannot consume immediately he considers valueless. His bodily needs (especially for sex) and his taste for 'action' take precedence over everything else - and certainly over any work routine." ${ }^{50}$ Such were the terms of debate by 1972 that Amitai Etzioni, director of the Center for Policy Research at Columbia University and writing in the Saturday Review, could suggest (in language that could also be read as racially-coded) that federally sponsored training programs that sought "to try to change" the "work behavior" of "disadvantaged" individuals were destined to fail because "human beings are not very easy to change after all" and that training programs would fare far better if they helped such persons "choose jobs compatible with their personalities" ${ }^{51}$ [Figure 2]. A circular argument emerged; people who lacked an ability to resist immediate satisfactions were more likely to fail in socioeconomic terms, while lower-class persons suffered from an inability to defer gratification. It was, as historian Alice O'Connor has noted, a "profile of lower-class personality disorders" that was "contradictory, culturally biased, and remarkably simplistic at times" and that yet continued to gain ground - at least among illiberal social policy researchers. ${ }^{52}$

Many social scientists were unconvinced. A widely cited article already in 1965 argued, for instance, that the so-called poverty and self-indulgence paradigm that used a "deferred gratification pattern" (DGP) to explicate "lower class behavior" was just "a thin reed on which to hang analyses of behavior" and that therefore DGP cannot be "mechanically applied to interpret low income life." The critique discussed previously unpublished social psychological research that tested the DGP; an experimenter promised candy to two randomly assigned groups of children from various racial and social backgrounds, but he then broke his promise to one of the two groups. When he repeated the experi- 


\section{HUMAN BEINGS ARE NOT VERY \\ EASY TO CHANGE AFTER ALL}

An unjoyful message and its implications for social programs

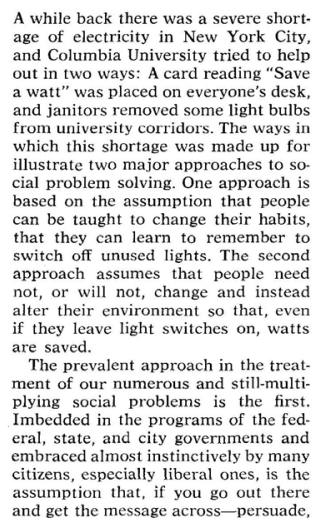

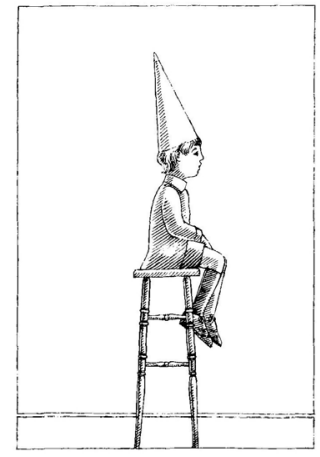

BY AMITAI ETZIONI

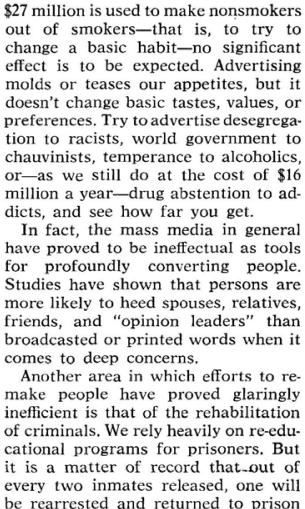

out cut smo effect is to be expected. Advertising molds or teases our appetites, but it doesn't change basic tastes, values, or preferences. Try to advertise desegrega chauvinists, temperance to alcoholics, -as we still do at the cost of $\$ 1$ dicts, and see how far you get.

In fact, the mass media in genera provod to be ineffectual as tools Studies have shown that persons are more likely to heed spouses, relatives, friends, and "opinion leaders than comes to deep concerns.

Another area in which efforts to re make people have proved glaringly of criminals. We rely heavily on re-edu every two inmates released, one will

Figure 2: Excerpt from Amitai Etzioni's "Human Beings Are Not Very Easy to Change After All," Saturday Review 55 (June 3, 1972): 45. Image used by permission of UNZ.org, 2016, and Amitai Etzioni.

ment, it was not class or race that determined a child's ability or inability to defer gratification but rather whether the child belonged to the group that had been deceived. "The situational variable, then, rather than class affiliation determined the ability to delay," this research found. The article concluded that "at the level of social science analysis, the verdict on the DGP is "not proven." And yet a commonsense view that jumbled causation (while being drenched in associations with both class status and racial identity) - and assumed that a person's inability to control his or her immediate impulses predicted that person's ability to succeed in life-simply refused to die.

\section{Self-Control and IQ}

By 1974, Mischel started to make more pronounced arguments about causation and not just correlation between class status and a demonstrated capacity for impulse control. He noted that the "middle and upper (in contrast to lower) socioeconomic classes" exhibited "higher intelligence, more mature cognitive development, and a greater capacity for sustained attention" and how "membership in the lower socioeconomic classes" correlated with lower levels of these same qualities. But he also began to itemize "the magnitude of the social 
problems" associated with "inadequate voluntary delay and deficiencies in selfcontrol." Despite his qualifying use of the word "partial," Mischel contended that "inadequate delay patterns" often were "the partial causes of antisocial and criminal behavior, violence and physical aggression, and failure to achieve reasonable work and interpersonal satisfactions." In sum, Mischel made what was at that point the most far-reaching case to date that "deficiencies in voluntary delay may become a major source of frustration by guaranteeing the individual an endless chain of failure in our culture." Indeed, Mischel here effectively did not shy from making the most grandiose claims for his marshmallow-derived findings, as now the fate of society itself was said to be at stake: "Basic to most philosophical concepts of 'will power' and the parallel psychological construct of 'ego strength' is the ability to postpone immediate gratification for the sake of future consequences, to impose delays of reward on oneself, and to tolerate such self-initiated frustration. It is difficult to conceive of socialization (or, indeed, of civilization) without such self-imposed delays." ${ }^{54}$ Although surely unintended by Mischel, these maneuvers opened up his research to a whole new range of ideological applications.

It was psychologist Richard J. Herrnstein who first imported a version of Mischel's concepts about self-imposed delays, socioeconomic class status, and "deviant" behavior into the discipline of criminology. In the late 1950s and early 1960s, Herrnstein had published animal research (with pigeons) on the use of variable-interval time-delayed reinforcements. ${ }^{55} \mathrm{He}$ had clearly followed the progress of Mischel's research. This would be confirmed in 1985 when, in Crime and Human Nature, a tome Herrnstein cowrote with political scientist James Q. Wilson, the authors not only offered favorable assessments of the longitudinal studies of Sheldon and Eleanor Glueck as well as sociologist Lee Robins but also and additionally made honorable mention of Mischel's social psychological research on delayed gratification. With an explicit reference to Mischel, the authors noted how "offenders are much more likely than nonoffenders to prefer an immediate small reward to a delayed larger one." And citing the same 1974 passage from Mischel quoted above, Herrnstein and Wilson portentously concluded how the "predisposition to impulsiveness" in children, "when combined with a family setting in which rewards and penalties are not systematically made contingent on behavior," in turn "leads to inadequate socialization" and places "a strain on civilization." ${ }^{\prime \prime 6}$ Mischel's impact on the text's analysis of what kind of person commits criminal acts was unmistakable - if also selectively skewed. The idea that familial breakdown led to deficiencies in self-control that, in turn, produced criminal behavior was not the viewpoint Mischel meant to promote, but his ideas proved very usable for an unabashedly right-wing causational theory.

There were equally tendentious efforts to cement connections between the (in)ability to delay gratification and a host of behavioral and cognitive issues. Mischel himself had initially proposed in 1962 that high delayers were on the whole more intelligent than poor delayers. ${ }^{57}$ But it was only in the course of the 
1980s that a full-blown "cognitive deficit" theory linking low IQ and weak impulse control to criminal behavior came to popular and scholarly fruition. Strikingly, here again the pronouncements of pigeon psychologist Herrnstein proved instrumental. ${ }^{58}$ But the grand leap from an inability to resist temptation to low IQ and a propensity to commit crimes made its boldest entrance only in 1990. "Criminal acts provide immediate gratification of desires," Michael R. Gottfredson and Travis Hirschi wrote that year in their milestone book, A General Theory of Crime, adding, "The cognitive requirements for most crimes are minimal." For Gottfredson and Hirschi, poor impulse control explained "all crime, at all times, and, for that matter, many forms of behavior that are not sanctioned by the state." For these authors, low self-control was "for all intents and purposes, the individual-level cause of crime," and furthermore "the search for personality correlates of crime other than self-control" was "unlikely to bear fruit." ${ }^{\prime 59}$ That blanket statements like these elicited strong reaction would be an understatement; A General Theory of Crime would be the most widely discussed (and critiqued) text in the field of criminology published in the past quarter century. ${ }^{60}$

If poor people possessed low impulse control and lower IQs and were more prone to criminal behavior, what might be asserted about the well-to-do? Was there no criminal malfeasance at the higher echelons? Herrnstein had argued at least since 1971 that US society was developing into a meritocracy with high IQ scorers dominating the upper class (and low IQ scorers slipping into the socioeconomic bottom rung) ${ }^{61}$ However, a position that the wealthy deserved their cozy status because they possessed the smartest genes truly came to prominence only with the publication of The Bell Curve. Here Herrnstein and political scientist Charles Murray popularized the concept of "cognitive stratification," arguing that IQ scores essentially determined individuals" economic fortunes in life. Why would a "cognitive elite" not float "toward the upper income brackets," Herrnstein and Murray pondered, as well as come to dominate "most of the institutions in society" while also acquiring "some of the characteristics of a caste"? ${ }^{62}$ Nor would Murray (after Herrnstein's death the same month in 1994 when The Bell Curve was published) ever be prompted to revise himself. On the contrary, Murray was back at it in 2012, observing how "cognitive segregation" was "bound to start developing" in the United States "as soon as unusually smart people began to have the opportunity to hang out with other unusually smart people." Brainy (and successful) parents quite simply produced brainy (and successful) children. This was so, Murray rhetorically declared, because brainy parents possessed both excellent foresight and self-discipline. "The children of the new upper class are the object of intense planning from the moment the woman learns she is pregnant," Murray noted. "She makes sure her nutritional intake exactly mirrors the optimal diet and takes classes (along with her husband) to prepare for a natural childbirth-a C-section is a last resort." Also after the birth, an upper-class mother behaved perfectly: "She breast-feeds her new-born, usually to the complete exclusion of formula, and tracks the infant's growth with the appropriate length and weight 
charts continually. The infant is bombarded with intellectual stimulation from the moment of birth. . . . The mobile over the infant's crib and the toys with which he is provided are designed to induce every possible bit of neural growth within the child's cerebral cortex."63

The well-to-do were experts at "intense planning" because they were bright, and well-to-do children were bright because their parents had been expert planners. And both talents taken together ensured the perpetuation of (what David Brooks in 2011 blithely labeled) "a hereditary meritocratic class" that successfully "passed down habits, knowledge, and cognitive traits" and thus successfully "reinforces itself through genes and strenuous cultivation generation after generation." ${ }^{64}$ Small wonder that disability studies scholar Michael Bérubé had already in the 1990s characterized Murray's vision of a world in which "unusually smart" parenting inevitably resulted in "unusually smart" children as nothing other than a glossy and updated version of social Darwinism. ${ }^{65}$ And yet as problematic as Murray's familial fantasies were, they nonetheless continued to accrue ideological weight and intellectual gravitas. ${ }^{66}$

If high IQ and high self-control often correlated, which was more significant? Was IQ the most important measure of future success, or was it character? On this point, not all education theorists were in agreement. In 1996, for instance, education professor Louis Goldman argued that "the development of character" was seldom achievable in a society "that legitimates the satisfaction of most appetites." Goldman relied on both Allison Davis and Walter Mischel but in iconoclastic ways. When Goldman asserted that "social class differences appeared to be largely a function of the ability to defer gratification," he went on directly to quote Davis from 1948 as evidence for the long-standing obviousness of his own point: "“In slum groups, both children and adults are permitted far more gratification of their sexual responses and of their rage responses. This . . extends into most of the basic areas of adolescent behavior in the lower classes.", (Davis, in fact, had argued for the reverse causation.) But then, and specifically citing Mischel, Goldman also summarized that "recent studies have described subjects with high ability to delay gratification as interested in intellectual matters, scoring better on intelligence tests, being academically competent, verbally fluent, rational, attentive, and better able to plan." What this meant, Goldman concluded, was how essential it was "to connect the lower social classes to the middle classes who may provide role models for self-discipline." ${ }^{67}$ Nonetheless, Goldman still assumed that intelligence test scores mattered.

\section{Self-Control and Education Reform}

There must have been extraordinary hunger for an alternative framework. Against the position of right-leaning social scientists that human nature was essentially intractable (and therefore that the liberal policy programs associated with the 1960s and early 1970s were doomed to failure), a new theory began to be formulated at the turn of the millennium: a theory of human nature that 
people could change - though by themselves and therefore without the crutch of a government-sponsored social welfare system. The notion of tractabilitywhich had been associated with the "social engineering" of liberal policy programs in the 1960s - had now itself shifted into a kinder, gentler, more politically muted (and less social and structurally oriented) psychological analysis. Theorists of self-control who counted themselves opposed to the right-wing perspective that personality was set in stone from birth (and was therefore genetic or in some other way biological) tended to operate on the premise that they had never met a self-regulating behavior they did not like.

Gone were the post-New Deal era theories that too much delay of gratification warped middle-class children, as adults and children alike were now being encouraged to master their impulses. But gone too was the 1990s conviction that IQ trumped all else. Instead, there were the new and immensely influential ideas of developmental psychologist Angela Duckworth. Duckworth had worked repeatedly with Mischel and turned what she learned about gratification delay into self-control exercises to help schoolchildren improve their academic performance. She also developed a so-called Grit scale to measure perseverance and motivation. Duckworth's philosophy was as simple as had been Mischel's initial marshmallow experiments. "There may be no such thing as 'too much' self-control," she said in $2011 .{ }^{68}$ But were race and class really gone?

An education reform movement took off that posited the value of cultivating the impulse control of children of all colors and socioeconomic backgrounds. Paul Tough's best-selling How Children Succeed: Grit, Curiosity, and the Hidden Power of Character (2012) became the movement's manifesto, as it also carefully linked psychological theories about self-control to a novel "cognitive hypothesis" buttressed by neuroscience that "what matters most in a child's development" is "not how much information we can stuff into her brain" but rather that "we are able to help her develop a very different set of qualities, a list that includes persistence, self-control, curiosity, conscientiousness, grit, and self-confidence." ${ }^{\prime 69}$ Tough relied extensively on Duckworth's research when he offered these conclusions.

Despite recurrent invocations of Mischel as a key authority, though, these new perspectives concerning the virtues of self-discipline did not have their origins solely in Mischel's work on delayed gratification. Another strand of thinking from the burgeoning field known as positive psychology blended into the work of the newest educational reformers. As psychologist Martin E. P. Seligman wrote in Learned Optimism (1991), a foundational text of the positive psychology movement, his view represented a rejection of the classic behavioral experiment involving reinforcements and rats. ${ }^{70}$ Give a rat a pellet every time he pressed a bar, and he will learn to press the bar to receive a pellet. Never give a rat a pellet every time he pressed a bar, and he will stop pressing the bar to receive a pellet. Give a rat a pellet only once in a while when he presses a bar, and he will continue to press the bar for a long while before complete "extinction" of this impulse takes over — and he quits pressing the bar. Seligman 
argued that this experiment with rats did not work with humans. Seligman concluded instead that human behavior was controlled "not just by the "schedule of reinforcement' in the environment but by an internal mental state, the explanations people make for why the environment has scheduled their reinforcements in this way." In terms of people's persistence, then, "what really mattered" was "the way people think about the causes of successes and failures," not so much whether they actually succeeded or failed. ${ }^{71}$ Rather than developing cognitive skills (like IQ), positive psychology directed attention toward "building and using your signature strengths" because "the good life is using your signature strengths every day to produce authentic happiness and abundant gratification," as Seligman wrote in Authentic Happiness: Using the New Positive Psychology to Realize Your Potential for Lasting Fulfillment (2002). ${ }^{72}$

As for the single most important predictor of personal achievement, Seligman and Duckworth together wrote in 2005 (based on a longitudinal study of more than 100 eighth graders) that it had virtually everything to do with "self-discipline": "We found that self-discipline predicted academic performance more robustly than did IQ. Self-discipline also predicted which students would improve their grades over the course of the school year, whereas IQ did not." ${ }^{\text {?3 }}$ In 2013, Duckworth was awarded the prestigious MacArthur Foundation grant for her research on the critical role that self-control played in educational achievement. Tough's and Duckworth's non-IQ approach impressively avoided the elitism (and, given the mutual imbrication of the class and racial stratifications in US society, the not-so-hidden racism) of Murray and Herrnstein. But that did not mean that there were not class- and race-based assumptions about the direction of causation between individual character development and life success built into the studies on which they grounded their theories.

\section{Conclusion}

The history of IQ is a history of social ideology, historian Paula Fass reminds us, even as she also observes that the IQ test initially served progressive ends. IQ, as it was developed in the first three decades of the twentieth century, introduced a metric for "what seemed to be the fairest and the most practical as well as the most culturally felicitous, organizing principle" to measure an individual's talent in an era of social upheaval and rapid cultural change. ${ }^{74}$ My essay has argued that the history of EI is also a history of social ideology and that self-control - "the master aptitude" that Goleman most associated with EI - has been an ambiguous concept intended to resolve dilemmas raised by the racialized assumptions that had by the 1990s come quite dramatically to taint the reputation of IQ testing. ${ }^{75}$ While IQ was said to be innate, EI was argued to be the opposite; EI could be acquired, its proponents argued, and it could be taught. And self-control was the principal marker of having achieved greater EI. In an article on EI in 1995, Time magazine made the connections clear. It not only opened its cover story on EI with a laudatory summary of the 
marshmallow test. ("It seems that the ability to delay gratification is a master skill, a triumph of the reasoning brain over the impulsive one.") It also went on uncritically to applaud the development of "emotional literacy" programs that were "designed to help children learn to manage anger, frustration, loneliness" as educators sought actively to reevaluate "the weight they have been giving to traditional lessons and standardized tests." twenty-first century) like IQ (in the first decades of the twentieth century) is a concept used to evaluate individuals in a fashion that (its advocates argue) is equitable and unbiased. That IQ was perceived to be a flawed metric only caused another metric to be invented. But when EI arrived on the scene, it did so with its own complicated and historically heavy ideological baggage, one ineluctably linked to the shifting meanings associated with self-control. This is the history that this essay has reconstructed.

The very concept of self-control had once been a profoundly racialized one. The way that coded, now-you-see-it-now-you-don't references to race have moved in and out of focus in the literature on self-control reveals much about the ideological work done by any social psychological theory that directs attention away from broader contexts and toward the individual's success or failure at self-management. But the concept of self-control was all along also very much a class-tied concept. Just as direct references to race largely disappeared by the 1990 s, so too a second great erasure would by the early twenty-first century remove explicit acknowledgment of socioeconomic status from the burgeoning literature on self-improvement. The seemingly universal address of the current injunctions to all individuals to upgrade their self-control skills masks how these ubiquitously repeated injunctions direct attention away from the open secret of (ever more rapidly widening) class divisions - and the descent of a (formerly more secure) middle class into greater and greater insecurity. In short, the history of gratification delay and EI is an important aspect of the history of race and of class in postwar America, even though many advocates of self-control still labor to camouflage that this is so.

\section{Notes}

1. See, for instance, Howard Gardner, Frames of Mind: The Theory of Multiple Intelligences (New York: Basic Books, 1983), and Peter Salovey and John D. Mayer, "Emotional Intelligence," Imagination, Cognition, and Personality 9 (1990): 185-211.

2. Salovey and Mayer, "Emotional Intelligence," 185.

3. Daniel Goleman, Emotional Intelligence (New York: Bantam, 1995), 56, 81, 285, 82.

4. See Walter Mischel and Carol Gilligan, "Delay of Gratification, Motivation for the Prohibited Gratification, and Responses to Temptation," Journal of Abnormal and Social Psychology 69 (October 1964): 415.

5. Among the details that varied in related experiments conducted by Mischel over the course of the $1960 \mathrm{~s}$, for instance, were not only the kinds of rewards offered but also such matters as whether the child experienced recurrent success in the task assigned to him or her whose completion would lead to reward, whether an adult playing an interactive game with a child modeled receiving his own rewards as rigorously as was expected of the child, and whether a higher or lower value was placed by the child on a reward if the child could expect ultimately to receive the reward than if the reward were unattainable. In the marshmallow (or penny or pretzel) experiments themselves, there were over time, and especially into the 1970s, variations in the types of supplementary stimuli offered (e.g., a slide show with images either relevant or irrelevant to the preferred reward 
chosen by the child) and/or (as a child's ability to self-distract either by fantasy and imagination or by focusing on something other than the anticipated reward came to be seen as a significant factor in the success in delaying gratification) variations in the kinds of distractions presented. Yet another variant on the marshmallow experiment involved preparatory conversations with the children about whether (and if so how) they might succeed in distracting themselves.

6. Walter Mischel, "Preference for Delayed Reinforcement: An Experimental Study of a Cultural Observation," Journal of Abnormal and Social Psychology 56 (January 1958): 57-61.

7. Walter Mischel, "Preference for Delayed Reinforcement and Social Responsibility," Journal of Abnormal and Social Psychology 62 (January 1961): 7.

8. Walter Mischel, "Delay of Gratification, Need for Achievement, and Acquiescence in Another Culture," Journal of Abnormal and Social Psychology 62 (May 1961): 543-52.

9. Walter Mischel, "Father-Absence and Delay of Gratification," Journal of Abnormal and Social Psychology 63 (July 1961): 117.

10. Goleman, Emotional Intelligence, 82, 83.

11. See Daniel Akst, Temptation: Finding Self-Control in an Age of Excess (New York: Penguin, 2011), and Joachim de Posada and Bob Andelman, Keep Your Eye on the Marshmallow! Gain Focus and Resilience-and Come Out Ahead in Hard Times (New York: Penguin, 2013). A typical passage from Keep Your Eye on the Marshmallow! is the following: "the global economy is coming out of its worst malaise since the Great Depression of the 1930s," and a new generation of individuals are facing the need to follow the "marshmallow principles"-because "every choice he makes, every marshmallow he savors or gobbles affects his wife, their two children, and even the family dog." Ibid., 2. This title by de Posada and Andelman is a sequel to Joachim de Posada and Ellen Singer, Don't Gobble the Marshmallow... Ever! The Secret Success in Times of Change (New York: Penguin, 2007), and Joachim de Posada and Ellen Singer, Don't Eat the Marshmallow ... Yet! The Secret to Sweet Success in Work and Life (New York: Penguin, 2005).

12. Daniel Goleman, "What Makes a Leader?," Harvard Business Review 76 (November/ December 1998): 93.

13. Erica Brown, Spiritual Boredom: Rediscovering the Wonder of Judaism (Woodstock, VT: Jewish Lights Publishing, 2009), 85.

14. Richard L. Peterson and Frank F. Murtha, MarketPsych: How to Manage Fear and Build Your Investor Identity (Hoboken, NJ: Wiley, 2010), 132.

15. For the first published account of the marshmallow test, see Walter Mischel, Ebbe B. Ebbesen, and Antonette Raskoff Zeiss, "Cognitive and Attentional Mechanisms in Delay of Gratification," Journal of Personality and Social Psychology 21 (February 1972): 204-18.

16. David Brooks, "Marshmallows and Public Policy," New York Times, May 7, 2006. See also David Brooks, “The Character Factory," New York Times, July 31, 2014.

17. Allison Davis, Social-Class Influences upon Learning (Cambridge, MA: Harvard University Press, 1948), 74.

18. Allison Davis, "The Socialization of the American Negro Child and Adolescent," Journal of Negro Education 8 (July 1939): 264. See also Allison Davis and Robert J. Havighurst, "Social Class and Color Differences in Child-Rearing," American Sociological Review 11 (December 1946): 698-710, and Michael R. Hillis, "Allison Davis and the Study of Race, Social Class, and Schooling," Journal of Negro Education 64 (Winter 1995): 33-41.

19. John Dollard, Caste and Class in a Southern Town (New Haven, CT: Yale University Press, 1937), 425-26, 427.

20. Martha C. Ericson, "Child-Rearing and Social Status," American Journal of Sociology 52 (November 1946): 192.

21. Robert J. Havighurst, "Child Development in Relation to Community Social Structure," Child Development 17 (March-June 1946): 87, 88.

22. Arnold W. Green, "The Middle Class Male Child and Neurosis," American Sociological Review 11 (February 1946): 35, 37, 38. Green's article was widely reprinted and often cited in the decades to follow. Betty Friedan's The Feminine Mystique (1963) would rely heavily on Green's analysis to buttress her scathing assessment of the miserable life of the middle-class housewife. See Betty Friedan, The Feminine Mystique (New York: Norton, 2001), 289-93.

23. Albert K. Cohen, Delinquent Boys: The Culture of the Gang (New York: Free Press, 1955), 89-90, 97-99.

24. David Matza and Gresham M. Sykes, "Juvenile Delinquency and Subterranean Values," American Sociological Review 26 (October 1961): 716. See also Gresham M. Sykes and David Matza, "Techniques of Neutralization," American Sociological Review 22 (December 1957): 664-70.

25. William H. Sewell, "Social Class and Childhood Personality," Sociometry 24 (December 1961): 350 .

26. Sheldon Glueck and Eleanor Glueck, Unraveling Juvenile Delinquency (New York: Commonwealth Fund, 1950), 282.

27. Or so the Gluecks themselves announced in 1959. See their summary in Sheldon Glueck and Eleanor Glueck, Predicting Delinquency and Crime (Cambridge, MA: Harvard University Press, 1959), 127-36. 
28. Charles Bennett, "Bronx Study Spots Likely Delinquents: City Study Spots Likely Bad Boys," New York Times, January 22, 1960, 1.

29. Lee N. Robins, "Sturdy Predictors of Adult Antisocial Behavior, Replications from Longitudinal Studies," Psychological Medicine 8 (1978): 611. See also Lee N. Robins, Deviant Children Grown Up: A Sociological and Psychiatric Study of Sociopathic Personality (Baltimore: Williams and Wilkins, 1966).

30. Glueck and Glueck, Predicting Delinquency and Crime, 59.

31. See Edward L. Thorndike, Educational Psychology, vol. 1, The Original Nature of Man (New York: Teachers College, Columbia University, 1913).

32. On rats as trial subjects, see Frank A. Logan, "The Role of Delay of Reinforcement in Determining Reaction Potential," Journal of Experimental Psychology 43 (June 1952): 393-99. On pigeons as trial subjects, see Charles B. Ferster, "Sustained Behavior under Delayed Reinforcement," Journal of Experimental Psychology 45 (April 1953): 218-24. A general summary of animal research on reinforcement delay can be found in Glenn Terrell, "Delayed Reinforcement Effects," in Advances in Child Development and Behavior, vol. 2, ed. Lewis P. Lipsitt and Charles C. Spiker (New York: Academic Press, 1965), 129-32.

33. A general summary of early research into reinforcement delay and human subjects can be found in K. Edward Renner, "Delay of Reinforcement: A Historical Review," Psychological Bulletin 61 (May 1964): 355-57.

34. Mischel, "Preference for Delayed Reinforcement," 57, 60.

35. See, for instance, O. H. Mowrer and A. D. Ullman, "Time as a Determinant in Integrative Learning," Psychological Review 52 (May 1945): 61-90, and J. B. Rotter, Social Learning and Clinical Psychology (New York: Prentice Hall, 1954).

36. Walter Mischel, Personality and Assessment (New York: Wiley, 1968), 167.

37. Mischel and Gilligan, "Delay of Gratification, Motivation for the Prohibited Gratification, and Responses to Temptation," 412.

38. Walter Mischel, The Marshmallow Test: Mastering Self-Control (New York: Little, Brown, 2014), 74.

39. Mischel and Gilligan, "Delay of Gratification, Motivation for the Prohibited Gratification, and Responses to Temptation," 412.

40. Daniel Patrick Moynihan, The Negro Family: The Case for National Action (Washington,

DC: Office of Policy Planning and Research, US Department of Labor, March 1965), 29.

41. Daryl Michael Scott, Contempt and Pity: Social Policy and the Image of the Damaged Black Psyche, 1880-1996 (Chapel Hill: University of North Carolina Press, 1997), 151-52.

42. See, for instance, the contributions to Lee Rainwater and William L. Yancey, eds., The Moynihan Report and the Politics of Controversy (Cambridge, MA: MIT Press, 1967).

43. Ellen Herman, The Romance of American Psychology: Political Culture in the Age of Experts (Berkeley: University of California Press, 1995), 205.

44. As Ryan wrote, "Moynihan was able to take a subject that had previously been confined to the Sociology Department seminar room, filled with aromatic smoke from judiciously puffed pipes, and bring it into a central position in popular American thought, creating a whole new set of group stereotypes which support the notion that Negro culture produces a weak and disorganized form of family life, which in turn is a major factor in maintaining Negro inequality." See William Ryan, Blaming the Victim (New York: Pantheon Books, 1971), 62.

45. In more recent years, there has been an argument that these criticisms caricatured Moynihan's actual viewpoints. See, for instance, James T. Patterson, Freedom Is Not Enough: The Moynihan Report and America's Struggle over Black Family Life-from LBJ to Obama (New York: Basic Books, 2010). For continued critical assessments of the Moynihan Report, see Leigh Mullings, On Our Own Terms: Race, Class, and Gender in the Lives of African American Women (New York: Routledge, 1997), 116-118, 161-162; and Melissa V. Harris-Perry, Sister Citizen: Shame, Stereotypes, and Black Women in America (New Haven, CT: Yale University Press, 2011), 93-94. 1964).

46. Thomas F. Pettigrew, A Profile of the Negro American (Princeton, NJ: Van Nostrand Co.,

47. Moynihan, The Negro Family, 39.

48. The only study I have found that mentions this aspect of the Moynihan Report is Alice O'Connor, Poverty Knowledge: Social Science, Social Policy, and the Poor in Twentieth-Century U.S. History (Princeton, NJ: Princeton University Press, 2001), 205.

49. Manpower Report of the President (Washington, DC: U.S. Government Printing Office, April 1968), 86.

50. Edward C. Banfield, The Unheavenly City: The Nature and Future of Our Urban Crisis (Boston: Little, Brown, 1968), 53.

51. Amitai Etzioni, "Human Beings Are Not Very Easy to Change After All," Saturday Review 55 (June 3, 1972): 47.

52. O’Connor, Poverty Knowledge, 110-11.

53. S. M. Miller, Frank Riessman, and Arthur A. Seagull, "Poverty and Self-Indulgence: A Critique of the Non-Deferred Gratification Pattern," in Poverty in America: A Book of Readings, ed. 
Louis Ferman et al. (Ann Arbor: University of Michigan Press, 1965), 286, 301, 300. The experiment cited had been conducted by Arthur A. Seagull. See also S. M. Miller and Frank Riessman, Social Class and Social Policy (New York: Basic Books, 1968).

54. Walter Mischel, "Processes in Delay of Gratification," in Advances in Experimental Social Psychology, vol. 7, ed. Leonard Berkowitz (New York: Academic Press, 1974), 253-54, 250.

55. See, for instance, R. J. Herrnstein, "Some Factors Influencing Behavior in a Two-Response Situation," Transactions of the New York Academy of Sciences 21 (November 1958): 35-45, and R. J. Herrnstein, "Relative and Absolute Strength of Response as a Function of Frequency of Reinforcement," Journal of the Experimental Analysis of Behavior 4 (July 1961): 267-72.

56. James Q. Wilson and Richard J. Herrnstein, Crime and Human Nature (New York: Simon and Schuster, 1985), 243.

57. Walter Mischel and Ralph Metzner, "Preference for Delayed Reward as a Function of Age, Intelligence, and Length of Delay Interval," Journal of Abnormal and Social Psychology 64 (June 1962): 425-31.

58. See Richard Herrnstein, "Some Criminogenic Traits of Offenders," in Crime and Public Policy, ed. James Q. Wilson (San Francisco: Institute for Contemporary Studies, 1983), 31-52.

59. Michael R. Gottfredson and Travis Hirschi, A General Theory of Crime (Stanford, CA: Stanford University Press, 1990), 89, 117, 232. See also Travis Hirschi, Causes of Delinquency (Berkeley: University of California Press, 1969).

60. See the excellent collection of essays in Erich Goode, ed., Out of Control: Assessing the General Theory of Crime (Stanford, CA: Stanford University Press, 2008).

61. Richard J. Herrnstein, IQ in the Meritocracy (Boston: Atlantic Little, Brown, 1971). See also Richard J. Herrnstein, "I.Q.," Atlantic 228 (September 1971), 43-64.

62. Richard J. Herrnstein and Charles Murray, The Bell Curve: Intelligence and Class Structure in American Life (New York: Free Press, 1994), 25, 113.

63. Charles Murray, Coming Apart: The State of White America, 1960-2010 (New York: Crown Forum, 2012), 53, 39.

64. David Brooks, The Social Animal: The Hidden Sources of Love, Character, and Achievement (New York: Random House, 2011), 107.

65. Michael Bérubé, Life As We Know It: A Father, A Family, and an Exceptional Child (New York: Pantheon Books, 1996), 246. As Berubé prophetically wrote in 1996 about his young Down syndrome son, "Among the many things I fear coming to pass in my children's lifetime, I fear this above all: that children like James will eventually be seen as 'luxuries' employers and insurance companies cannot afford, or as 'luxuries' the nation or the planet cannot afford. I do not want to see a world in which human life is judged by the kind of cost-benefit analysis that weeds out those least likely to attain self-sufficiency and to provide adequate 'returns' on social investments." Ibid., 52.

66. Writing in January 2012, Brooks gushed, "I'll be shocked if there's another book this year as important as Charles Murray's 'Coming Apart.' I'll be shocked if there's another book that so compellingly describes the most important trends in American society." David Brooks, "The Great Divorce," New York Times, January 30, 2012, A25.

67. Louis Goldman, "Mind, Character, and the Deferral of Gratification," Educational Forum 60 (Winter 1996): 135-40.

68. Angela L. Duckworth, "The Significance of Self-Control," PNAS 108 (February 15, 2011): 2639. See also this rhetorical query from positive psychologists Christopher Peterson and Martin E. P. Seligman: "Is there a downside to self-regulation? Thus far, we are unaware of any undesirable consequences or correlates of high self-control." There was really no such thing as "excessive self-control (over-control)." Christopher Peterson and Martin E. P. Seligman, Character Strengths and Virtues: A Handbook and Classification (New York: Oxford University Press, 2004), 508.

69. Paul Tough, How Children Succeed: Grit, Curiosity, and the Hidden Power of Character (Boston: Houghton Mifflin Harcourt, 2012), xv.

70. Seligman's early research involved laboratory experiments with rats. See, for instance, Martin E. Seligman, "Chronic Fear Produced by Unpredictable Electric Shock," Journal of Comparative and Physiological Psychology 66 (October 1968): 402-11.

71. Martin E. P. Seligman, Learned Optimism (New York: Knopf, 1991), 40-41.

72. Martin E. P. Seligman, Authentic Happiness: Using the New Positive Psychology to Realize Your Potential for Lasting Fulfillment (New York: Free Press, 2002), 13.

73. Angela L. Duckworth and Martin E. P. Seligman, "Self-Discipline Outdoes IQ in Predicting Academic Performance of Adolescents," Psychological Sciences 16 (December 2005): 942.

74. Paula S. Fass, "The IQ: A Cultural and Historical Framework," American Journal of Education 88 (August 1980): 436.

75. Goleman, Emotional Intelligence, 78.

76. Nancy Gibbs and Sharon E. Epperson, “The EQ Factor,” Time, October 2, 1995. 